\title{
A Review of Microinvasive Combined Phaco- Vitrectomy: Recent Technical Advances
}

\author{
Andrea Mercanti · Antonio Renna
}

Received: March 1, 2017 / Published online: March 29, 2017

(C) The Author(s) 2017. This article is an open access publication

\begin{abstract}
Combined cataract and vitreoretinal surgery results in better compliance in patients with posterior segment pathology and should be the preferred approach to reduce the high rate of cataract development after vitreoretinal surgery and to improve earlier visual acuity. Technological advances in both anterior and posterior segment surgery are leading to the development of instruments with a smaller diameter and more efficient tools, resulting in a minimizing of the tissue trauma related to the surgery, acceleration of functional recovery and increasing patient comfort. In this review we report on recent advances that allow this miniaturization process while maintaining the efficacy and safety of microinvasive combined surgical procedures, with a focus on pumps, illumination, phaco tip and the vitrectomy probe.
\end{abstract}

Enhanced content To view enhanced content for this article go to http://www.medengine.com/Redeem/ 19F7F0606B42CE1D.

A. Mercanti $(\square)$

Eye Unit, Treviglio Hospital, Treviglio, BG, Italy

e-mail: andreamercanti.vr@gmail.com

A. Renna

Studi Medici Renna, Melendugno, LE, Italy
Keywords: Combined phaco-vitrectomy; Microinvasive surgery; Surgical tool

\section{INTRODUCTION}

Technological advances in the instrumentation used in ocular surgeries are leading to the development of instruments with a smaller diameter and more efficient tools. In vitreoretinal surgery, there has been a gradual shift from instruments with a diameter of $20 \mathrm{G}$ to those with smaller diameters as a strategy to reduce intraoperative and postoperative complications $[1,2]$. Similarly, in anterior segment surgery, smaller, sutureless and self-sealing corneal incisions are more comfortable and equally safe for the patient as the standard approach [3]. Combined cataract and vitreoretinal surgery has been investigated with the aim to achieve a better compliance and to reduce the risk of multiple inflammatory eye stress in patients with significant cataract concomitant with posterior segment pathology. According to previous studies, cataract surgery combined with vitrectomy should be preferred to reduce the high rate of cataract development after vitreoretinal surgery and to improve earlier visual acuity $[4,5]$. With all of these developments, it is crucial for modern ophthalmic surgery systems to provide the best solutions for both anterior and posterior segment surgery. 
The aim of this review is to illustrate a number of recent advances in this field.

\section{METHODS}

A search of PubMed was made using the search string "Cataract Extraction" [Mesh] AND ("Vitrectomy" [Mesh] OR "Vitreoretinal Surgery" [Mesh]) AND "combined" [text] NOT "Glaucoma" [Mesh] AND ("2007/03/02" [PDat]: "2017/02/26" [PDat])", and articles dealing with new technologies in ocular surgery were selected. Data on novel devices for anterior and posterior segment surgeries were searched among ophthalmology books, papers presented during international congresses or published in ophthalmological tabloids with an acknowledged Editorial Board scientific surveillance control and published in the last 10 years. The identified articles were then divided into subsequent sections and topics on different aspects of microinvasive combined ocular surgery (abstract, introduction, methods, pumps, illumination, phaco tip, vitrectomy probe, conclusion and references). The abstract, full article and references were obtained and the references further checked for additional material where appropriate. This review does not contain any new studies with human or animal subjects performed by any of the authors.

\section{PUMPS}

The physics of doing surgery with smaller instruments requires that higher infusion and aspiration values and a precise control of flow be maintained to achieve an efficiency comparable to that of previous systems used in both anterior and posterior surgeries [6, 7]. While shaving the vitreous base, an excess of fluid acceleration should be avoided. This fluid acceleration is generally higher when a peristaltic pump is used, depending on vacuum changes, and could lead to retinal traction and tears [8]. A Venturi pump allows a lower acceleration, controlling the flow via vacuum, with the final resulting flow depending on viscosity and thus not directly controlled. Recently,
OERTLI ${ }^{\circledR}$ introduced with the OS4 platform (Oertli Instrumente AG, Berneck, Switzerland) with the SPEEP mode, which allows maximum values for flow and vacuum to be set independently. This platform consists of a peristaltic pump that mimics a Venturi-based system; the flow is controlled by the movement of the wheel and the vacuum is controlled by a sensor in the cassette [9]. The big advantage of SPEEP mode is an instant availability of data on the preset flow and the control of the vacuum through the pedal, leading to an impressive control of the holding forces. In our experience, this capability allows more precision and accuracy in maneuvers such as lifting of the epi-nucleus in cataract surgery, aspiration of membranes and sub-luxated lens particles in the vitreous and in peripheral vitrectomy, especially over a detached retina.

The EVA platform (DORC International B.V., Zuidland, The Netherlands) has a Valve Timing intelligence (VTi) aspiration system for vitrectomy surgery, designed specifically to overcome the limitations of both peristaltic and Venturi pressure systems thanks to a series of sensitive computer-controlled operating pistons and closure valves working in very small flow chambers. The EVA system allows the user to decide between two different modes by the touch of a button: vacuum or flow control mode. In vacuum mode, the pistons work at high speed to build and maintain the desired vacuum value. In flow control mode, the valves operate at a precalculated speed to achieve the desired flow. Compared to a Venturi-driven vitrectomy system, the EVA VTi machine generates a much faster rise time in vacuum mode. Unlike a conventional rotary peristaltic system, the pressure output that is generated by the EVA VTi instrument in flow control vitrectomy does not exhibit oscillations, producing improved fluidic stability overall [10].

An important safety issue related to pumps is intraocular pressure management in order to avoid damage to the optic nerve during surgery. In the literature values of ocular perfusion pressure of the ophthalmic artery of $>30 \mathrm{mmHg}$ are considered to be safe, and therefore desirable, while $50 \mathrm{mmHg}$ is deemed ideal $[11,12]$. The R-Evolution CR platform (OPTIKON 2000, 
Inc., Rome, Italy) is able to calculate patient mean ocular perfusion pressure and to dynamically stabilize the intraocular pressure during surgery using a controlled-pressure irrigation system that offers real-time compensation of pressure fluctuations, informing the surgeons in real-time and allowing them to take decisions concerning the infusion pressure [13].

Another interesting feature allowing the surgeon to independently control two continuous functions simultaneously-for example, fragmentation power and vacuum-is the dual-linear footpedal integrated in the Stellaris PC platform (Bausch \& Lomb, Inc., New York, NY). Dual-linear control is particularly useful in intraoperative floppy iris syndrome and in zonulopathy during cataract surgery, as well as in removing dislocated lens fragments. In a recent survey, surgeons using this technology report improvements in holdability, chamber stability, followability, chatter reduction and cutting power, minimization of post-occlusion surge, volumes of irrigation fluid used and ultrasound power and a reduction of mean actual phaco time and effective phaco time, compared with co-linear control [14].

\section{ILLUMINATION}

In vitreoretinal surgery, intraocular illumination is achieved by fibers penetrating into the eye. Two conventional variants are available. The stiff handheld fiber allows a bright and targeted illumination of a limited area, whereas the chandelier endoilluminator enlightens the whole intraocular space, even the very peripheral areas. Smaller diameters reduce the luminous flux transmitted by the light guide. On the other hand, the maximum exposure time, the maximum power densities and its spectral distribution have to be taken into account to reduce retinal damage. Conventional xenon light sources exhibit intensive emission in the blue part of their spectrum that is responsible for the photochemical harm of these light sources, whereas almost all wavelengths in the visible spectrum contribute to thermal damage [15]. The recent advances in LED technology have resulted in the development of light sources which reach a brightness comparable to that of xenon or mercury light sources but which have eliminated or reduced those damaging components of the spectrum, thereby reducing the photochemical and thermal hazards. The DORC EVA, OPTIKON R-Evolution and OERTLI OS4 platforms allow the component of the spectrum to be chosen according to surgeon preference and his own perception of the surgery. In our experience a prevalence of the blue component allows a better visualization of the vitreous due to the Rayleigh scattering in the core vitrectomy, in which the light probe is not so close to the retina. Alternatively, a prevalent amber light is safer when the light probe is close to the retina and allows a better visualization of brilliant blue-stained membranes and in the presence of intraocular air. Hessling et al. proposed a trans-scleral approach consisting of a flat top LED fixed to an eye speculum and pressed against the eye at the pars plana by a thread without any incision; however, further evaluations are needed to understand the capability of this technique [16].

\section{PHACO TIP}

Microinvasive cataract surgery refers to a complete surgical procedure through a corneal tunnel with a width of $\leq 1.8 \mathrm{~mm}$, allowing a very low surgically induced astigmatism [3]. A major issue in this case is chamber stability, which has to be achieved with an infusion capacity that is far above that of the outflow [6]. Other requirements of ideal cataract surgery are followability-i.e. a constantly strong inflow of the infusion directly to the tip-and holdability, which requires high vacuum strength. The dual-linear footpedal by Bausch \& Lomb has already been studied as a means to improve these issues. The last advance in this field, proposed by Oertli Instrumente, is the easyPhaco ${ }^{\circledR}$ technology that uses a capillary suction channel with an open cross-section that is half the size of that used in the standard equipment, thereby increasing the outflow resistance [17]. At the same time, the width of the incision remains unchanged, allowing an enlarged cross-sectional area for the inflow and a drop of the flow 
resistance for the infusion. This technology provides an exceptional chamber stability even when very high vacuum settings are used to improve followability and holdability. A wider head cross-section with a larger opening area has been designed not only to improve holdability but also to maximize the ultrasound energy delivery.

Alcon Laboratories Inc., (Fort Worth, TX) developed the OZil IP torsional technology that optimizes energy delivery during surgical procedures and integrated this technology in the Centurion platform with the INTREPID balanced tip. This tip is specifically designed for torsional ultrasound with a 50\% enhancement in sideways tip displacement and reduces the amount of energy transmitted to the sleeve and incision site. Torsional phacoemulsification had been shown to require less ultrasound energy in comparison to the longitudinal system and differs from it in two aspects: (1) the frequency of the phacoemulsification tip in the torsional mode $(32 \mathrm{kHz})$ is $80 \%$ of that in the conventional phacoemulsification $(40 \mathrm{kHz})$ and (2) the stroke length of the phacoemulsification tip in the torsional mode $(40 \mu \mathrm{m})$ is $50 \%$ of that in the standard mode $(80 \mu \mathrm{m})$. All of these improvements make the Centurion platform more efficient than its predecessor, the Infiniti platform [18]. Assil et al. compared torsional ultrasound of Infiniti with transverse ultrasound of Ellips FX Transversal Ultrasound embedded in the WhiteStar Signature system (Abbott Medical Optics, Inc., Santa Ana, CA) and came to the conclusion that the latter was more efficient in cataract surgery. Thus, further studies are needed to compare the more recent torsional and transverse ultrasound systems to determine which one is the more efficient [19].

\section{VITRECTOMY PROBE}

Vitreoretinal surgery has undergone an outstanding rate of innovations in recent years, probably because instrumentation miniaturization presents even more challenges in dealing with a non-Newtonian fluid-like vitreous. The refining of vitrectomy probes in terms of cut rate and the more accurate control of duty-cycle have the aim to reduce an excess of fluid acceleration [7]. A better control of duty-cycle is achieved by the dual pneumatic systems that use two separate air line tubes to open and close the cutter [20]. The improvement in cut rate means that smaller and more easily aspirated pieces of vitreous are produced. This could be achieved with the twin duty-cycle cutters, in which the guillotine blade carries out two cuts per work step, leaving the aspiration window permanently open, thus decoupling cut rate from aspiration flow [21]. This technology has been adopted by several platforms: Optikon R-Evolution CR, DORC EVA, OERTLI OS4. The pulse-free flow makes duty-cycle management obsolete. A new promising approach to vitrectomy is currently in development by Bausch \& Lomb and aims to increase the vitrectomy cut rate from around 12,000-16,000 per minute with today's machines to approximately 1.7 million cuts per minute [22]. This result would be possible using hypersonic liquefaction, with the mounting of a single-needle on a piezoelectric transducer element that vibrates harmonically, first cutting and then aspiring vitreous, thereby avoiding retinal traction.

\section{CONCLUSION}

Recent technical improvements in microinvasive combined surgery allow the diameters of incisions in both anterior and posterior segment surgeries to be reduced without any reduction of the efficiency and safety of procedures. In the last decade, these technical advances have contributed to a great improvement in ocular surgery. Smaller instruments have been developed, resulting in notably improved surgical performances. At the same time, visualization systems have been improved that allow the surgeon to operate on the posterior segment independently even under highly challenging conditions. These improvements do not seem to be over. In the coming months/years we can expect innovations that could revolutionize eye surgery, especially in the posterior segment. The final objective is to minimize tissue trauma related to surgery, 
accelerate functional recovery and increase patient comfort.

\section{ACKNOWLEDGMENTS}

No funding or sponsorship was received for this study or publication of this article. All named authors meet the International Committee of Medical Journal Editors (ICMJE) criteria for authorship for this manuscript, take responsibility for the integrity of the work as a whole, and have given final approval to the version to be published. This paper was based in part on a presentation at the ESCRS 2016.

Disclosures. Andrea Mercanti and Antonio Renna have nothing to disclose.

Compliance with Ethics Guidelines. This article does not contain any new studies with human or animal subjects performed by any of the authors.

Data Sharing. Data sharing is not applicable to this article as no datasets were generated or analyzed during the current study.

Open Access. This article is distributed under the terms of the Creative Commons Attribution-NonCommercial 4.0 International License (http://creativecommons.org/licenses/by-nc/4. $0 /$ ), which permits any noncommercial use, distribution, and reproduction in any medium, provided you give appropriate credit to the original author(s) and the source, provide a link to the Creative Commons license, and indicate if changes were made.

\section{REFERENCES}

1. Misra A, Ho-Yen G, Burton RL. 23-gauge sutureless vitrectomy and 20-gauge vitrectomy: a case series comparison. Eye. 2009;23(5):1187-91.

2. Kellner L, Wimpissinger B, Stolba U, et al. 25-gauge vs 20-gauge system for pars plana vitrectomy: a prospective randomised clinical trial. $\mathrm{Br} \mathrm{J}$ Ophthalmol. 2007;91(7):945-8.
3. Shentu $X$, Zhang $X$, Tang $X, Y u$ X. Coaxial microincision cataract surgery versus standard coaxial small-incision cataract surgery: a meta-analysis of randomized controlled trials. PLoS One. 2016;11(1):e0146676.

4. Lee JY, Jeong HS, Lee DY, et al. Early postoperative intraocular pressure stability after combined 23-gauge sutureless vitrectomy and cataract surgery in patients with proliferative diabetic retinopathy. Retina. 2012;32(9):1767-74.

5. Savastano A, Savastano MC, Barca F, Petrarchini F, Mariotti C, Rizzo S. Combining cataract surgery with 25-gauge high-speed pars plana vitrectomy results from a retrospective study. Ophthalmology. 2013;121(1):299-304.

6. Alió JL, Rodriguez-Prats JL, Galal A. Chapter 6: micro-incision cataract surgery (MICS). In: Espaillat Jr A, Agarwal A, Lindstrom R, editors. Recent trends in cataract management, vol. 1. Panama: Jaypee-Highlights Medical Publishers, Inc.; 2012. p. 99-114.

7. Steel DHW, Charles S. Vitrectomy fluidics. Ophthalmologica. 2011;226[Suppl 1]:27-35.

8. Rossi T, Querzoli G, Angelini G, et al. Introducing new vitreous cutter blade shapes: a fluid dynamics study. Retina. 2014;34(9):1896-904.

9. Wolf A. New design elements boost vitrectomy efficiency. Retina Today. 2016;11(2):28-30.

10. Stalmans P. Enhancing visual acuity. In: $\mathrm{Oh} H$, Oshima Y, editors. Microincision vitrectomy surgery. Emerging techniques and technology. Dev Ophthalmol, vol. 54. Basel: Karger; 2014. p. 23-30.

11. Liu JH, Gokhale PA, Loving RT, Kripke DF, Weinreb RN. Laboratory assessment of diurnal and nocturnal ocular perfusion pressures in humans. J Ocul Pharmacol Ther. 2003;19(4):291-7.

12. Sehi M, Flanagan JG, Zeng L, Cook RJ, Trope GE. Anterior optic nerve capillary blood flow response to diurnal variation of mean ocular perfusion pressure in early untreated primary open-angle glaucoma. Invest Ophthalmol Vis Sci. 2005;46(12):4581-7.

13. Rossi T, Querzoli G, Angelini G, et al. Ocular perfusion pressure during pars plana vitrectomy: a pilot study. Invest Ophthalmol Vis Sci. 2014;55(12):8497-505.

14. Krader CG. Surgeons favor dual-linear foot pedal for efficiency in difficult cases. Ophthalmology Times. March 01, 2016. http://ophthalmologytimes. modernmedicine.com/ophthalmologytimes/news/ 
surgeons-favor-dual-linear-foot-pedal-efficiencydifficult-cases?page=0,0. Accessed on Feb 26, 2017.

15. Koch FHJ, Schmidt HP, Mönks T, Blumenröder S, Haller A, Steinmetz RL. The retinal irradiance and spectral properties of the multiport illumination system for vitreous surgery. Am J Ophthalmol. 1993;116(4):489-96.

16. Hessling M, Koelbl PS, Lingenfelder C, Koch F. Miniature LED endoilluminators for vitreoretinal surgery. In: Lilge LD, Sroka R, editors. Proc. SPIE Vol. 9542. Medical laser applications and laser-tissue interactions VII. Munich: SPIE; 2015. p. 95421A1-9.

17. Gandorfer A. easyPhaco ${ }^{\circledR}$ technology-a quantum leap. Eur Ophthalmic Rev. 2010;4(1):51-3.

18. Chen M, Anderson E, Hill G, Chen JJ, Patrianakos T. Comparison of cumulative dissipated energy between the Infiniti and Centurion phacoemulsification systems. Clin Ophthalmol. 2015;9:1367-72.
19. Assil KK, Harris L, Cecka J. Transverse vs torsional ultrasound: prospective randomized contralaterally controlled study comparing two phacoemulsification-system handpieces. Clin Ophthalmol. 2015;9:1405-11.

20. Diniz B, Ribeiro RM, Rodrigo BF, et al. Fluidics in a dual-pneumatic ultra high-speed vitreous cutter system. Ophthalmologica. 2013;229(1):15-20.

21. Rossi T, Querzoli G, Angelini G, et al. Instantaneous flow rate of vitreous cutter probes. Retina. 2014;55(12):8289-94.

22. Roberts CW. Presentation transcripted in: $B+L$ shares developments in vitrectomy. August 29, 2016. http://ois.net/bausch-and-lomb-sharesdevelopments-in-vitrectomy/. Accessed Feb 26, 2017. 